ISSN: 1982-1263

\title{
Definição estratégica para uma empresa de pequeno porte no ramo agrícola
}

Gabriela Lange Cardoso ${ }^{1}, \underline{\text { Melissa Watanabe }}{ }^{2 *}, \underline{\text { Miguelangelo Gianezini }}^{3}$

${ }^{l}$ Graduada em Administração de Empresas - Linha de Formação Específica em Administração de Empresas Universidade do Extremo Sul Catarinense - UNESC.

${ }^{2}$ Doutora em Agronegócios pela UFRGS, professora pesquisadora do Programa de Pós Graduação em Desenvolvimento Socioeconômico da Universidade do Extremo Sul Catarinense - PPGDS/UNESC.

${ }^{3}$ Doutor em Agronegócios pela UFRGS, professor pesquisador do Programa de Pós Graduação em Desenvolvimento Socioeconômico da Universidade do Extremo Sul Catarinense - PPGDS/UNESC.

*Autor para correspondência: E-mail: melissawatanabe@unesc.net

RESUMO. O presente estudo caracteriza-se pela análise da gestão estratégica de uma empresa de pequeno porte do ramo agrícola. O trabalho teve como objetivo estudar a gestão estratégica de uma empresa de rações para animais, baseando-se em um arcabouço teórico referente ao agronegócio, cadeia produtiva da carne bovina e o planejamento estratégico. A metodologia da pesquisa é caracterizada como exploratória descritiva, sendo que os dados analisados foram coletados no mês de setembro de 2013. A pesquisa foi desenvolvida por meio de entrevistas em profundidade realizada com os gestores da empresa. A tendência de que cada gestor observa e toma decisões em para verificar o ambiente interno e externo da organização. Com os resultados obtidos na pesquisa foi possível identificar a percepção dos gestores relacionados à importância de buscar e efetuar uma gestão estratégica formalizada para o bom desempenho e para a própria sustentabilidade da empresa em estudo.

Palavras-chave: Planejamento estratégico, agronegócio, MPE

\section{Strategic setting for a small business of the agricultural sector}

\begin{abstract}
This study is characterized by analyzing the strategic management of a small business in the agricultural industry. The work was given to study strategic management of a company feed large animals. Based on a theoretical framework, regarding the agribusiness production chain of beef and strategic planning. The research methodology is characterized as descriptive, exploratory, and the data analyzed were collected in September 2013. The research was conducted through in-depth interviews with company managers. The tendency of each manager observes and makes decisions regarding the internal and external environment of the organization. With the results obtained in the study were able to identify the perception of managers related to the importance of seeking and make a formalized strategic management for good performance and the sustainability of the company under study.
\end{abstract}

Keywords: Strategic planning, agribusiness, MPE

\section{Introdução}

O Brasil possui características favoráveis para o agronegócio, pois possuem diversos tipos de clima, alta incidência de luz solar, chuvas regulares, solos férteis, entre outros. Esses fatores fazem o país apresentar vocação natural para o ramo agrícola e todos os negócios relacionados às cadeias produtivas agropecuárias.

Uma área que está em forte crescimento no país acompanhando o desenvolvimento agropecuário é a de rações animais. Neste ramo procura-se obter cada vez maior eficácia, para que $\mathrm{o}$ produtor alcance uma rentabilidade adequada para a sustentabilidade de seus negócios.

O agronegócio brasileiro está em evolução, associado diretamente ao desenvolvimento científico-tecnológico, modernização rural, expansão agroindustrial, programas de sanidade animal e políticas de incentivos agrícolas (Toledo \& Simões, 2010). Desta forma, deve haver cada vez mais a necessidade de planejamentos, investimentos e de melhor organização para que tal expansão possa ocorrer de forma sustentável. 
Mas para que isso aconteça, é necessário que tanto o produtor rural quanto as empresas da área agrícola busquem um bom gerenciamento, utilizando ferramentas administrativas que possibilitem uma visão holística da empresa, visando uma otimização da interação com o ambiente, agindo de forma competitiva e estratégica, destacando-se dos demais concorrentes

Diante disso, as empresas que procuram manter-se no mercado e obter bons lucros precisam buscar o aperfeiçoamento e aprimoramento constante, sendo necessária a utilização de um planejamento estratégico para o próprio negócio.

O planejamento estratégico é um processo administrativo que por meio de estudos e de estratégias, possibilita que a empresa alcance suas metas e objetivos. Assim, define-se planejamento estratégico como um processo de desenvolvimento e manutenção de uma estratégia, entre os objetivos e a capacidade da empresa, levando em consideração possíveis mudanças e novas oportunidades de mercado (Kotler, 1993).

Ao aplicar esta definição ao setor agrícola verifica-se que em pequenas empresas e na própria área há certas dificuldades na elaboração e na execução de planos estratégicos. Isso ocorre normalmente pela falta de recursos das empresas na contratação de profissionais especializados na área administrativa, pelo excesso de tarefas operacionais do próprio gestor dentre outros fatores.

No Brasil a taxa de mortalidade das empresas nos primeiros dois anos de atividade é de $26,9 \%$ (SEBRAE, 2011). Em alguns Estados o índice de falências é ainda maior, como observado por Ferreira (2006), em Pernambuco, 42\% das empresas fechou as portas antes de completar dois anos. Entende-se que um dos principais fatores agravantes para a falência de uma empresa é a ausência do planejamento estratégico.

Diante disso, definiu-se o objetivo do trabalho, apresentar a importância do planejamento estratégico para uma empresa de pequeno porte no ramo de ração animal para bovinos.

A empresa na qual se desenvolveu o estudo, localiza-se no município de Forquilhinha - SC, inserida em uma área rural, porém próxima ao meio urbano. Criada em agosto de 2010, com o intuito de satisfazer a demanda de componentes nutricionais de animais de grande porte.

\section{Fundamentação teórica}

\section{A agricultura e o agronegócio}

Ao longo da história da humanidade houve transformações significativas na agricultura, sobretudo com o avanço da tecnologia. $\mathrm{O}$ que antigamente era dividido em setor primário, secundário e terciário, com o tempo foi se modificando, pois o chamado setor primário começou a depender de outros serviços, gerando assim novos segmentos (Araújo, 2007).

O agronegócio é composto das empresas fornecedoras de insumos para as propriedades, dos produtores rurais, das indústrias, dos distribuidores e dos prestadores de serviços (Neve et al., 2005). Em complemento, Scolari (2005) afirma que o agronegócio brasileiro possui muitos pontos fortes que garantem competitividade no mercado: recursos humanos com profissionais qualificados, boa capacidade de gestão na produção e comercialização, oferta ambiental favorável, bom nível de desenvolvimento tecnológico, alta capacidade de produção de maquinaria agrícola, colheitadeiras e tratores e baixo custo de produção.

Desta forma, pode-se observar que o Brasil possui um enorme potencial para o agronegócio. Visto também que sua tendência é crescer cada vez mais, sendo impulsionado principalmente pela constante ampliação de novas tecnologias voltada para essa área.

Conforme indicam Vilela \& Macedo (2002) no processo de desenvolvimento tecnológico residem as maiores oportunidades para o aumento da qualidade e redução de custos dos produtos do agronegócio, o que pode igualmente representar um ganho estratégico.

\section{Cadeia produtiva da bovinocultura de corte $e$ leite}

No âmbito da bovinocultura, para que se obtenham resultados positivos, são necessários cuidados especiais, que vão desde o manejo da pastagem, passando pelos cuidados no início da vida do animal até que a carne chegue ao consumo. Fatores como a escolha da raça, sexo e nutrição são de extrema importância para definir a qualidade da carne e do leite. Já na cadeia produtiva de animais de grande porte, verifica-se uma extensa estrutura interligada, composta por 
diversas etapas, conforme a Figura 1.

Atualmente, destaca-se nesta cadeia o segmento da nutrição animal, pois é evidente que para que a carne bovina tenha qualidade e cumpra os requisitos de grande parte dos consumidores ou então haja uma boa produtividade de leite da criação de gado leiteiro é necessário que o animal tenha uma boa alimentação, rica em nutrientes que possam garantir seu excelente desenvolvimento.

Conforme explica Silva (2012) a nutrição animal é definida pelo conjunto de processos em que um organismo vivo digere ou assimila os nutrientes contidos nos alimentos, usando-os para seu crescimento, reposição ou reparação dos tecidos corporais e também, para elaboração de produtos (ex.: produção de leite e carne).

Figura 1. Representação esquemática da cadeia produtiva da carne bovina.

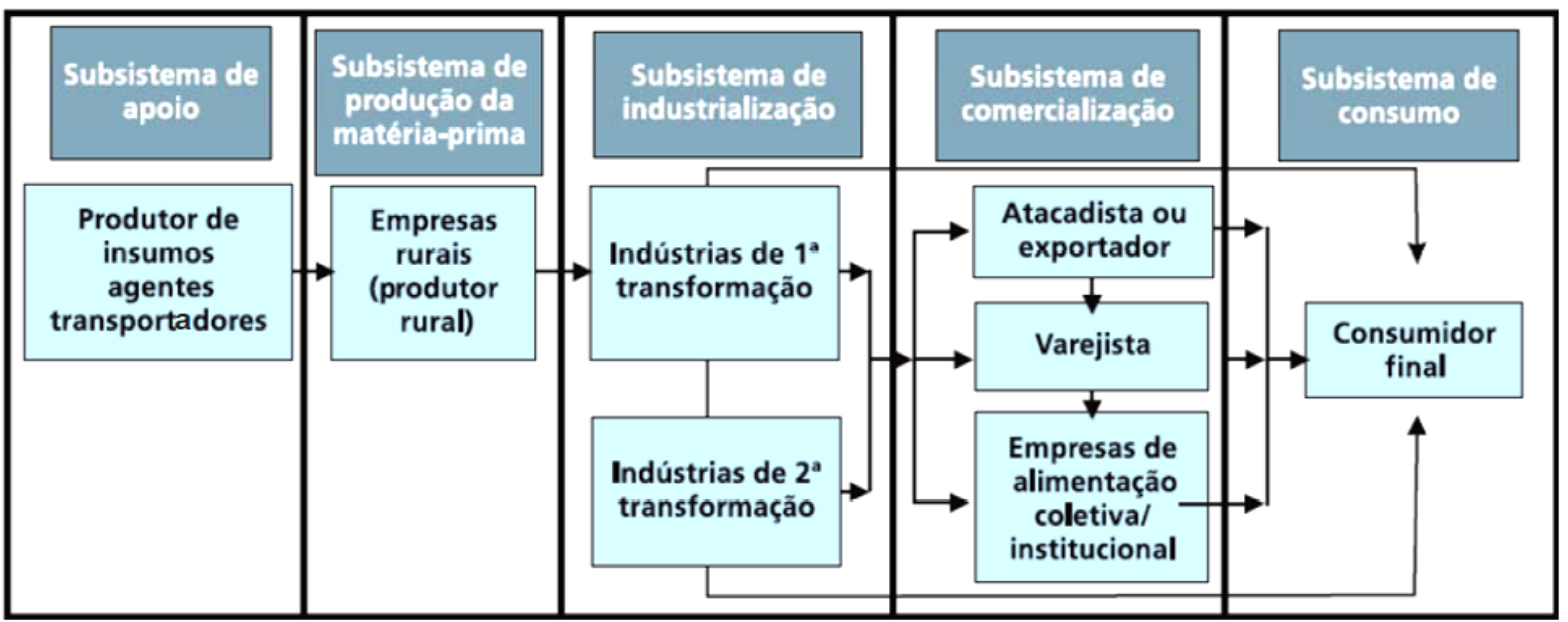

Fonte: Buainain \& Batalha (2007)

Sendo assim, observa-se que o principal objetivo da nutrição animal é alcançar às necessidades dos animais, contribuindo no ciclo de crescimento, em melhor desempenho e produção de baixo custo, evitando riscos à sociedade consumidora de produtos de origem animal.

Como lembra Silva (2012) para uma alimentação animal balanceada é necessário à presença de fibras, proteínas, carboidratos, vitaminas e minerais em proporções adequadas para a digestão. Sendo que cada um desses componentes tem um papel fundamental dentro do processo metabólico de acordo com o grau de exigência. A exigência é definida de acordo com a categoria do animal (cria, recria, engorda e gado de leite).

Um gargalo atual para a gestão estratégica do produtor rural está relacionado às pastagens, pois a forragem exige manejo do solo, controle de pragas e também é afetado por fatores exógenos, como o clima. Em algumas épocas do ano, como no inverno, há uma escassez de pastagens, pois a baixa temperatura prejudica o desenvolvimento fisiológico e vegetativo.Com a ausência das pastagens,o produtor precisa recorrer a produtos nutricionais para manter a alimentação equilibrada do animal. Como explica Rodrigues (1997), em meses frios e secos do ano, onde as condições são adversas, torna-se necessário buscar alternativas que são capazes de reduzir o impacto da escassez de forragem.

Os produtos que podem suprir as necessidades alimentares do animal são a soja, o milho, o trigo, o arroz, a mandioca e o algodão. Destes produtos, a soja é o principal produto na nutrição animal, representado pelo farelo de soja e casca de soja, sendo classificados como uma rica fonte de proteínas, produto de boa qualidade e de baixo custo.

As proteínas são ricas em carbono, hidrogênio, fósforo, oxigênio, elementos essenciais para a vida do animal (Morrison, 1966). Portanto todos os animais necessitam receber uma quantidade de proteína, pois ela forma o principal constituinte do organismo do animal, sendo, indispensável para o crescimento, à reprodução e a produção. Assim contribui para o melhor crescimento e desenvolvimento do animal e consequentemente de todo o rebanho, trazendo maior lucratividade ao produtor. 
Luchiari Filho (2006) observa que o Brasil encontra-se em destaque como grande produtor de carne bovina, sendo que a cadeia tem um peso significante no PIB brasileiro gerando somente em divisas, cerca de 5,5 bilhões de dólares com exportação de carne, calçados e couro.

Segundo dados obtidos do relatório de junho de 2014 divulgado pelo Departamento de Agricultura dos Estados Unidos (USDA), (observados na Tabela 1) Brasil, Índia e Austrália aparecem como os três maiores países exportadores de carne bovina,com maior destaque para o Brasil, que lidera as exportações do setor.

Buainain \& Batalha (2007) afirmam que a crescente dominação do mercado mundial de carne bovina pelo Brasil não é um fenômeno de curto prazo, e que os investimentos em gado e na indústria da carne permanecerão fortes à medida que o Brasil mantém seu foco orientado para as exportações. De maneira que a tendência do mercado da carne bovina é aumentar cada vez mais, observa-se que existirá também um amplo mercado para venda de produtos que garantam melhor qualidade da carne bovina.

Tabela 1. Carne Bovina - Exportação mundial 2007/2014, em milhões de toneladas equivalentes a carcaça

\begin{tabular}{|l|c|c|c|c|c|c|c|c|c|c|}
\hline \multicolumn{1}{|c|}{ PAís } & $\mathbf{2 0 0 7}$ & $\mathbf{2 0 0 8}$ & $\mathbf{2 0 0 9}$ & $\mathbf{2 0 1 0}$ & $\mathbf{2 0 1 1}$ & $\mathbf{2 0 1 2}$ & $\mathbf{2 0 1 3}$ & $\mathbf{2 0 1 4}$ & $\begin{array}{c}\text { Var(\%) } \\
(\mathbf{1 4 / 1 3 )}\end{array}$ & $\begin{array}{c}\text { Part. (\%) } \\
\mathbf{2 0 1 4}\end{array}$ \\
\hline Brasil & $\mathbf{2 , 1 9}$ & $\mathbf{1 , 8 0}$ & $\mathbf{1 , 6 0}$ & $\mathbf{1 , 5 6}$ & $\mathbf{1 , 3 4}$ & $\mathbf{1 , 5 2}$ & $\mathbf{1 , 8 5}$ & $\mathbf{2 , 0 3}$ & $\mathbf{9 , 7 3 \%}$ & $\mathbf{2 1 , 3 5}$ \\
\hline Índia & 0,68 & 0,67 & 0,61 & 0,92 & 1,27 & 1,41 & 1,77 & 1,88 & $5,93 \%$ & 19,72 \\
\hline Austrália & 1,40 & 1,41 & 1,36 & 1,37 & 1,41 & 1,41 & 1,59 & 1,56 & $-1,89 \%$ & 16,40 \\
\hline Estados Unidos & 0,65 & 0,91 & 0,88 & 1,04 & 1,26 & 1,11 & 1,17 & 1,14 & $-2,56 \%$ & 11,99 \\
\hline Nova Zelândia & 0,50 & 0,53 & 0,51 & 0,53 & 0,50 & 0,52 & 0,53 & 0,54 & $1,89 \%$ & 5,68 \\
\hline Uruguai & 0,39 & 0,36 & 0,38 & 0,35 & 0,32 & 0,36 & 0,34 & 0,39 & $14,71 \%$ & 4,10 \\
\hline Canadá & 0,46 & 0,49 & 0,48 & 0,52 & 0,43 & 0,34 & 0,33 & 0,36 & $9,09 \%$ & 3,79 \\
\hline Paraguai & nd & 0,23 & 0,25 & 0,30 & 0,21 & 0,25 & 0,33 & 0,35 & $6,06 \%$ & 3,68 \\
\hline UE - 27 & 0,14 & 0,2 & 0,15 & 0,34 & 0,45 & 0,3 & 0,24 & 0,24 & $0,00 \%$ & 2,52 \\
\hline Argentina & 0,53 & 0,40 & 0,62 & 0,28 & 0,21 & 0,16 & 0,19 & 0,22 & $15,79 \%$ & 2,31 \\
\hline México & 0,04 & 0,04 & 0,05 & 0,1 & 0,15 & 0,20 & 0,16 & 0,18 & $12,50 \%$ & 1,89 \\
\hline Outros & 0,45 & 0,57 & 0,58 & 0,54 & 0,54 & 0,58 & 0,67 & 0,625 & $-6,72 \%$ & 6,57 \\
\hline TOTAL & $\mathbf{7 , 6 3}$ & $\mathbf{7 , 6 2}$ & $\mathbf{7 , 4 7}$ & $\mathbf{7 , 8 4}$ & $\mathbf{8 , 1 2}$ & $\mathbf{8 , 1 6}$ & $\mathbf{9 , 1 7}$ & $\mathbf{9 , 5 1}$ & $\mathbf{3 , 7 1 \%}$ & $\mathbf{1 0 0 , 0 0}$ \\
\hline
\end{tabular}

Fonte:USDA, 2014

(*) Estimativa USDA - Jun/14

nd = Não Disponível

Assim tornam-se favoráveis, os investimentos ligados à produtos que tragam tais benefícios para a alimentação animal, beneficiando também aqueles que vivem da renda da sua criação, as agroindústrias e todos os elos envolvidos neste segmento. A melhoria na gestão estratégica de toda a cadeia trás maior competitividade e melhores ajustes na troca de informação entre os seus stakeholders.

\section{Planejamento estratégico}

Kaplan \& Norton (2004) iniciaram as pesquisas referentes à estratégia estudando como eram efetuados os mapas estratégicos de aproximadamente 300 organizações e também estudaram seu estágio de conhecimento em seus vários campos da gestão, incluindo valor dos stakeholders, estratégia do negócio e da corporação, gestão de clientes, desenvolvimento e inovação de produtos, planejamento operacional, investimento social, gestão de recursos humanos, planejamento de tecnologia de informação, cultura e liderança (Kaplan \& Norton, 2004).

Assim, o papel da estratégia é valorizado quando a velocidade das mudanças torna-se extremamente rápida, as tecnologias apresentam avanços imprevisíveis e os competidores encontram-se por toda parte, conduzindo ao pensamento de abertura de novos caminhos (Cavalcanti, 2007).

Segundo Mintzberg et al. (2000), a estratégia provê consistência, pois a estratégia é necessária para reduzir a ambiguidade e prover ordem. Desta forma, uma estratégia é como uma teoria: ou seja, uma estrutura cognitiva que existe para simplificar e explicar o mundo e com isso facilitar a ação.

Para Oliveira (2004), o planejamento estratégico pode ser definido, como um processo 
desenvolvido que possibilita alcance de uma situação desejada, focando em um modo mais eficiente, eficaz e efetivo, sendo ainda um processo contínuo, que será executado por pessoas que fazem parte do nível estratégico da empresa. $\mathrm{O}$ planejamento estratégico envolve o modo de pensar das pessoas, levando a possíveis questionamentos, como o que será feito, como será realizado, quando, quanto, para que, porque e onde será desenvolvido.

De acordo com Bilibio (2009), nos dias atuais, em uma empresa que apresenta ausência de objetivos claros, a tendência é que cada parte da gestão tome decisões por conta própria, acreditando estar fazendo o melhor, que pode ser para um determinado setor, mais não para a organização como um todo.

Conforme explicação de Barbalho (1997), o planejamento estratégico consiste na utilização eficaz dos meios disponíveis, na organização para exploração de condições favoráveis existentes no meio ambiente externo e interno que se efetiva através da gestão estratégica. As estratégias podem variar de acordo com o ambiente, a forma de atuação, a cultura, os interesses e os valores de cada organização (Rocha,1995). A Figura 2 ilustra o funcionamento do processo da administração estratégica

Figura 2. O processo de administração estratégico

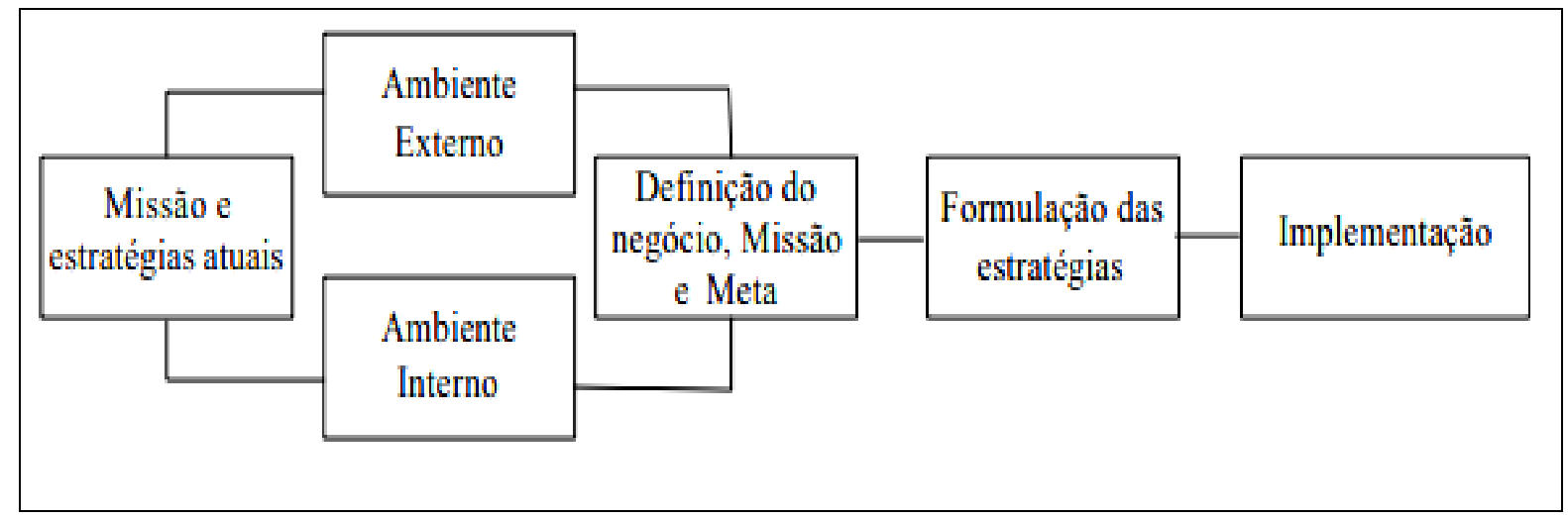

O planejamento quando bem executado poderá auxiliar, na definição de seus objetivos, encontrando possibilidades de crescimento, identificando o perfil da empresa, a visão, os valores, o estabelecimento de metas, análise dos pontos fortes e fracos, na administração do tempo e também auxiliando a gerência na tomada de decisões.

Para Oliveira et al.(1998), a especificação da missão, visão e dos seus valores está relacionada à definição do motivo para a existência da empresa, que de certa forma será uma justificativa social que dá sustentação às suas condutas. Assim, a empresa deve ser considerada como um meio para um fim.

Segundo a concepção de Porto (1997), a visão de uma empresa deve retratar um estado futuro que a mesma deseja alcançar, respeitando sua missão, a organização deve gerar uma visão que a retrate. Ou seja, a definição de visão está vinculada a uma questão: "o que a empresa procura ao longo deste caminho pela missão?"
Já os valores de uma organização são definidos por elementos que definem a importância das coisas, representam também uma predeterminação consciente da ação e das atitudes dos indivíduos.

O diagnóstico estratégico por sua vez é composto pela análise dos fatores externos e internos da empresa, por meio dessas análises são obtidas as oportunidades, as ameças, forças e fraquezas da empresa.

Segundo Campos (2011), é no diagnóstico estratégico que são feitos levantamentos da atual situação da empresa, buscando assim avaliar a existência de estratégias utilizadas, bem como se estas estão atendendo os resultados esperados.

$\mathrm{Na}$ análise externa é observado o ambiente no qual a empresa encontra-se inserida, verificando as ameças e as oportunidades encontradas no ambiente fora da própria empresa, para assim concretizar a visão, missão e os valores da organização.

Já na análise interna,são apontados pontos fortes e fracos, envolvendo os recursos e as 
carências da organização. Pois é necessário que a empresa tenha conhecimento sólido de seus produtos, mercados, de sua estrutura organizacional, colaboradores, clientes e de forma geral de sua própria história (Godet et al., 2000).

Uma ferramenta importante para a gestão estratégica que auxilia na identificação de fatores internos e externos presentes em uma organização é a Matriz SWOT. Dantas \& Melo (2008), afirmam que a análise SWOT é um sistema simples utilizado para verificar a posição estratégica da empresa. É uma sigla oriunda do inglês formando um acrônico de Forças (Strengths), Fraquezas (Weaknesses), Oportunidades (Opportunities) e Ameaças (Threats). A Figura 3 apresenta um modelo representativo de uma matriz SWOT com seus aspectos internos e externos e as dinâmicas as quais estão relacionados.
Após efetuar a análise de diversos pontos referentes à organização, inicia-se a etapa de formulação estratégica, sendo iniciada com a definição dos objetivos da empresa, pois são elementos que identificam de forma clara e precisa o que a empresa deseja e pretende alcançar. A partir dos objetivos, são definidas as metas da empresa.

A principal função das metas é o monitoramento do progresso da empresa. Para cada meta deve existir um plano operacional, que é um conjunto de ações. Toda meta estabelecida deve também conter até que ponto a empresa deseja chegar. Faz-se necessário que seja elaborado um plano para se atingir as metas estabelecidas, ou seja, a empresa precisará estabelecer estratégias para serem implantadas na organização.

Figura 3. Modelo de Matriz SWOT.

\begin{tabular}{|l|l|l|}
\hline & Contribui para a estratégia de sua empresa & Dificulta a estratégia de sua empresa \\
$\begin{array}{l}\text { Aspectos } \\
\text { internos }\end{array}$ & S: Quais são os pontos fortes de seu negócio? & $\mathrm{W}:$ Quais são os pontos fracos do seu negócio? \\
\hline $\begin{array}{l}\text { Aspectos } \\
\text { Externos }\end{array}$ & $\begin{array}{l}\text { O: Quais são as oportunidades para o seu } \\
\text { negócio? }\end{array}$ & T: Quais são as ameaças para seu negocio? \\
\hline
\end{tabular}

Fonte: Adaptado de Risk Management Agency, USDA (2014)

Após o estabelecimento das estratégias primordiais da empresa, nota-se que é necessário adotar programas e parcerias com as áreas e as pessoas envolvidas, determinando prazos para a realização das estratégias e dos recursos que serão utilizados. Conforme forem sendo realizadas as estratégias, a empresa deverá acompanhar os resultados. Segundo Quadros et al. (2012) a avaliação faz-se necessária, uma vez que, a empresa faz parte de ambientes em constante mudança e dessa forma os objetivos de hoje podem estar defasados amanhã.

\section{Planejamento estratégico em pequenas empresas}

Existem diversos autores que estudam e conceituam o planejamento estratégico em organizações de grande porte, entretanto poucos são os estudos e análises voltadas para o planejamento estratégico de pequenas e médias empresas, conforme ressalta Almeida (2009).

Segundo Tiffany \& Peterson (1998), a receita e a taxa de crescimento das pequenas empresas que possuem planos estratégicos são, em média, $50 \%$ superiores às empresas que optam pela não utilização do planejamento estratégico. É 
verificado também que $80 \%$ dos problemas existentes em pequenas empresas são de origem estratégica, enquanto apenas $20 \%$ resultam de insuficiência de recursos.

Com efeito, a pequena empresa é considerada o segmento que mais necessita do planejamento estratégico, pelo fato de que seus recursos são limitados e quando houver um único erro, este poderá dar início ao fracasso da empresa. Porém pode-se dizer que o planejamento estratégico não vem sendo muito utilizado no segmento das pequenas empresas, pois boa parte de sua metodologia foi desenvolvida focada em grandes empresas.

Outro fator que se torna relevante, é em relação ao envolvimento que a gerência das pequenas empresas tem com a própria produção e todos os demais processos existentes na mesma, o que ocasiona na falta de tempo disponível para o desenvolvimento de planos estratégicos.

Desta maneira é fundamental buscar o entendimento das características que as pequenas empresas apresentam, em um primeiro momento, observando a realidade da empresa, ressaltando suas características e limitações, para posteriormente propor formas adequadas para que o pequeno empresário consiga desenvolver estratégias organizacionais.

\section{Procedimentos metodológicos}

Neste estudo para os fins da investigação adotou-se pesquisa descritiva. Quanto aos meios de investigação, optou-se por pesquisa Bibliográfica, Documental e Estudo de Caso.

Os dados para o desenvolvimento da pesquisa são oriundos de dados primários e as técnicas de coleta utilizadas foram qualitativas. Utilizado como técnica a entrevista em profundidade, na qual foram desenvolvidas perguntas voltadas para a percepção das expectativas almejadas baseadas na literatura, e das expectativas para o futuro da empresa, sendo direcionados e aplicados aos dois gestores da mesma.

A análise dos dados obtidos foi feita por meio de observação e análise das respostas dos gestores, gravadas em áudio e transcritas de forma fiel, resultando em um total aproximado de 95 minutos.

A pesquisa foi realizada em uma empresa de distribuição de componentes nutricionais de animais de grande porte. Os principais produtos oferecidos pela empresa são milho, resíduo de milho e produtos derivados da soja, como é caso da casca de soja e o farelo de soja. O processo da empresa inicia com a aquisição dos produtos à granel, vindos de outros estados, como Rio Grande do Sul, Paraná e Mato Grosso do Sul. Após chegarem à empresa, os produtos são embalados, vendidos e entregues nas propriedades rurais ou em comércios agropecuários. O gerenciamento da organização é efetuado por dois sócios, um sócio majoritário e outro sócio gerente, atualmente a empresa conta com seis colaboradores.

A empresa busca manter como vantagem competitiva com a entrega imediata de seus produtos e prima por um relacionamento diferenciado com seus clientes e fornecedores buscando se adequar às necessidades.

Vale destacar que a organização estudada não possui planos estratégicos fundamentados e transcritos, apenas contam com o planejamento estratégico empírico, se apoiando em fatos e experiências vividas. A pesquisa possibilitou a observação entre o elo que há entre a teoria e a prática do planejamento estratégico em empresas de pequeno porte.

A metodologia utilizada para a realização dos questionários foi subdividida em tópicos, sendo eles: Intenções Estratégicas, Análise SWOT e a definição de metas e objetivos.Após subdividir os tópicos, foram elaboradas perguntas com uma linguagem clara possibilitando assim um maior aprofundamento dos temas questionados. Além das perguntas ao realizar a entrevista, foram exibidas aos gestores tabelas e figuras com a finalidade de um melhor entendimento de quais informações seriam necessárias para a realização do presente trabalho.

No texto os gestores entrevistados foram identificados como Gestor 1 e Gestor 2, sendo gestor 1 o sócio majoritário que faz visitas mensais a empresa para conferência e análise das vendas, e o gestor 2 , sendo o sócio gerente que atualmente controla diariamente todos os processos existentes no ambiente da empresa.

\section{Resultados e Discussão}

Neste tópico serão abordadas as intenções estratégicas como as metas, objetivos, missão e visão da empresa em estudo e de acordo com os gestores entrevistados. No tópico seguinte será abordada a análise SWOT, descrevendo seus pontos fortes e fracos, oportunidades e ameaças. 


\section{Intenções estratégicas}

Para que fosse possível definir as intenções estratégicas da empresa, foi necessário um questionamento sobre a própria história da organização.

Conforme explica Certo (1993), missão organizacional é a proposta para a qual, ou a razão pela qual uma organização existe, sendo uma declaração muito ampla da diretriz organizacional. Á vista disso, para definir a missão foi feita uma análise do que a empresa desenvolve, para quem elabora seus produtos, dos motivos pelos quais a empresa foi criada e dos processos existentes até que o produto chegue ao consumidor final. Para observar a visão da empresa foi questionado de que forma a gerência almejaria a empresa no futuro, e para finalizar foi questionado a quais valores a empresa procurava se basear, para assim definir os valores e princípios da mesma.

Identificou-se que a empresa comercializa produtos agropecuários, sendo que neste processo realiza a compra do produto a granel de indústrias fornecedoras de soja. Ao chegar à empresa, o produto passa pelo processo de embalagem, revenda e entrega. Os produtos comercializados são desenvolvidos especialmente para produtores rurais e também para comércios agropecuários, atualmente cada parte representa respectivamente $50 \%$ das vendas. Sua existência se deve ao fato de garantir a produção da carne bovina e da produção de leite, proporcionando ao produtor rural um melhor custo-benefício.

Segundo a percepção dos gestores entrevistados a empresa está em crescimento contínuo e quer ser vista como uma empresa séria que busca o aperfeiçoamento para atender cada vez mais e melhor às necessidades dos consumidores.

Baseiam-se na valorização de seus clientes, facilitando o dia a dia da clientela, buscando excelência no atendimento, criando elos de amizade com clientes e fornecedores, valorizando também a organização dos processos internos e o reconhecimento dos funcionários.

Abaixo destacam-se as intenções estratégicas elaboradas para a empresa estudada, conforme Quadro 1.

Quadro 1. Intenções estratégicas para empresa estudada

\begin{tabular}{|l|l|}
\hline Missão & $\begin{array}{l}\text { "Possibilitar ao produtor rural e a comércios agropecuários a comodidade em seu dia a } \\
\text { dia, entregando com eficiência e rapidez produtos que irão fidelizar clientes e } \\
\text { contribuir diretamente na qualidade da criação de animais". }\end{array}$ \\
\hline Visão & $\begin{array}{l}\text { Sendo referência na distribuição de alimentos agrícolas, reconhecida pela excelência } \\
\text { em seu atendimento ao cliente e por sua eficiência nas entregas de mercadorias. }\end{array}$ \\
\hline Valores & $\begin{array}{l}\text { Transparência nos relacionamentos } \\
\text { Ética e integridade } \\
\text { Eficiência }\end{array}$ \\
\hline$\quad \begin{array}{l}\text { Valorização humana } \\
\text { Excelência no atendimento }\end{array}$ \\
\hline
\end{tabular}

Fonte: Elaborado pela autora

\section{Análise SWOT}

Devido ao fato de alguns gestores saberem ou utilizarem somente de maneira empírica a Análise SWOT, optou-se nesta seção pela apresentação, de maneira explicativa e ilustrativa, do conceito da análise.

Desta forma, a pesquisadora apresentou aos gestores a metodologia utilizada para buscar extrair as melhores respostas. Baseou-se no modelo de Análise SWOT (Risk Management Agency, USDA 2014), feito por meio de ilustração e explicação descrevendo suas etapas, e os motivos pelos quais ela é considerada uma ferramenta importante no plano estratégico. Em seguida foi apresentando uma tabela de Análise do Ambiente Interno, que possibilitou ao gestor selecionar as opções que mais se assemelhavam a sua própria empresa. 
Conforme dados obtidos por meio da presente pesquisa, no ambiente interno pode-se verificar que ambos os sócios tem percepções convergentes, considerando que as principais forças da empresa estão na qualidade dos produtos oferecidos e dos profissionais com quem trabalham na facilidade de pagamento e na eficiência das entregas.

Considerou como fraquezas da empresa a escassez e a distância dos fornecedores, admitindo que o único transporte utilizado seja o rodoviário, o que impacta diretamente no preço de venda dos produtos.

Pode-se notar que a venda dos produtos ocorre de forma sazonal, sendo considerada uma fraqueza, assim como afirma Rodrigues (1997). A sazonalidade existe, por que no verão há pastagens naturais o que dificulta a venda dos produtos. Segundo informações obtidas com o gestor 2 devido a sazonalidade há uma queda de $30 \%$ nas vendas.

Segundo a percepção do gestor 1 a principal fraqueza da empresa está na ausência de um número maior de funcionários. Assim há a escassez de tempo para a prospecção de novos clientes e da fidelização dos atuais através de um pós venda, fazendo-se necessário um atendimento exclusivo ao produtor rural, para que se conheçam as propriedades de seus clientes e que os clientes conheçam os benefícios do mix de produtos, despertando assim o seu interesse em investir e em se tornar um cliente fidelizado. Porém para isso é necessário, um número maior de colaboradores, treinamentos aos novos e antigos funcionários e tempo disponível direcionado à visitas nas propriedades rurais. Porém ainda essas estratégias trazem um custo alto para a empresa.

Como forma de obter respostas objetivas sobre aspectos externos que possuem relação direta com a empresa, foi elencado vários temas que possibilitaram a observação do elo que há entre a empresa foco da pesquisa e os diversos agentes externos (stakeholders) que podem influenciar a empresa, sendo eles: mão de obra, concorrência, consumidores, comunidade, tecnologia, sindicatos, sistema financeiro, fornecedores e governo, conforme Dantas \& Melo (2008).

No que tange à mão de obra, ambos os gestores concordam que a mesma é um gargalo atual. A ausência desta oferta se deve a diversos motivos, entre eles: por ser um trabalho que exige esforço físico, por ser uma região pólo de empresas de grande porte e que uma parte significativa da população encontra-se empregada.

Com relação à concorrência, ambos os sócios consideram a concorrência baixa,como analisado positivamente por Kim \& Mauborgne (2005). No geral seus concorrentes trabalham para outras empresas, sendo representante, o que se diferencia do trabalho realizado pela empresa em estudo.

Corroborando com Buainain \& Batalha (2007), os entrevistados também declaram que o mercado encontra-se em expansão, e que os consumidores são produtores rurais e proprietários de comércios agrícolas. Mas cabe ressaltar certas características que diferenciam estas duas categorias de clientes. Como exemplo, o gestor 2 aponta que o produtor rural apresenta um maior processo de fidelização, pois considera-se um elo mais amigável entre o cliente e a empresa, normalmente estes estão dispostos a pagar um valor mais alto pelo produto. Já com os comerciantes não há fidelização e sempre buscam o preço mais acessível, porém a empresa se destaca, pois possui sempre produtos disponíveis em estoque.

Com relação à comunidade, os gestores contribuem através de patrocínios em festas locais, preferencialmente de temática agropecuária. No que tanger à tecnologia, o gestor 1 acredita que por ser somente um comércio, considera investimentos na área algo desnecessário, já o gestor 2 relata que há pouca presença da tecnologia na empresa mais que futuramente tem pretensão de investir.

Quanto aos sindicatos, os dois gestores relatam certo descontentamento do trabalho oferecido, afirmando que somente cobram as mensalidades e que nada fazem para contribuir com as empresas. Já sobre o sistema financeiro os gestores procuram obter estabilidade financeira, deixando maior parte do lucro para investimentos na própria organização. Atualmente a empresa trabalha com vendas à vista e a prazo, sendo que a maioria das vendas é feita a prazo e as compras à vista e atualmente o índice de inadimplência é considerado baixo.

No que se refere aos fornecedores, o gestor 1 relata que há muitos, porém a empresa procura trabalhar com fornecedores que ofereçam um 
produto de qualidade elevada. Já o gestor 2 afirma que não se encontra satisfeito com seus atuais fornecedores, pois acredita que são os fornecedores que deviam procurar seus clientes, o que não vem acontecendo na empresa, onde a mesma precisa ir sempre em busca de novos fornecedores.Porém, estes estão localizados à longas distâncias e não há fidelização entre fornecedores e empresa.

Em relação ao Governo, ambos os sócios dizem que é difícil falar sobre esse tema. Relatam ser totalmente a favor dos impostos, porém os inúmeros casos de desvios de dinheiro público são revoltantes.

O gestor 2 explica que há um grande número de praças de pedágio, isso faz com que haja um aumento no preço dos produtos. Alega também que é injusto o fato da carne bovina (produto final) ter isenção de PIS e COFINS e serem cobrados normalmente os impostos dos produtos necessários para a sua produção.

Quadro 2. Análise SWOT da empresa pesquisada.

\section{FORÇAS}

- Produtos e profissionais que visam à qualidade;

- Rapidez e eficiência na entrega;

- Facilidade de pagamento.

\section{FRAQUEZAS}

- Poucos fornecedores;

- Sazonalidade das vendas;

- A venda tem custo alto pela exclusividade no atendimento.

\section{OPORTUNIDADES}

- Expansão da Linha de Produtos;

- Trabalhar também com representações;

- Aquisição de sede própria.

\section{AMEAÇAS}

- Crescimento limitado do negócio, devido aos poucos fornecedores.

Fonte: Elaborado pela autora

Já o gestor 1 comentou acreditar que a maior oportunidade para as empresas são as pessoas, e que com a boa vontade sempre haverá oportunidades. Já o gestor 2 observou as oportunidades como incrementos físicos da empresa, como investir em uma linha de produtos mais diversificada, optando por fazer negociações com outras distribuidoras que trabalham com produtos diferentes dos quais a empresa vem comercializando, como aborda Kim \& Mauborgne (2005).

$\mathrm{O}$ gestor 1 garantiu não haver ameaças, dizendo não ter concorrentes e sim aliados e que tudo dependerá exclusivamente de cada pessoa. Considerou a concorrência um fator interessante para as empresas, pois assim haverá necessidade de aprimoramento, e explicou que utiliza a concorrência existente como uma ferramenta de estudo de mercado. Já, no ponto de vista do gestor 2 o crescimento limitado do mercado, ocorre devido aos poucos fornecedores e é cogitado como a maior ameaça para o desenvolvimento da empresa.

Com os resultados obtidos por meio da presente pesquisa e por Dantas e Melo (2008), apresenta-se a seguir um quadro síntese (Quadro
4) da Matriz SWOT, embasado no quadro da agência de risco e planejamento vinculada à USDA (Risk Management Agency/USDA, 2014), com às informações coletadas nas entrevistas aos gestores.

\section{Definição de objetivos e metas}

Nesta seção apresenta-se a pesquisa, onde foram definidos os objetivos e as metas da empresa. As perguntas foram realizadas provocando respostas de objetivos e metas empresariais a curto, médio e longo prazo, e também ressaltando os atuais objetivos da empresa, mostrado tal importância por Bilibio (2009).

Sem objetivos o comportamento das organizações podem tomar qualquer direção, pois são os objetivos que fornecem o fundamento para o planejamento, organização, motivação e controle (Certo, 1993).

Ao iniciar esta etapa da pesquisa observou-se uma restrição maior nas respostas obtidas, supondo que se tratando de metas e objetivos, evidenciam-se sonhos e questões particulares de cada indivíduo, o gestor 1 deixou claro que era difícil falar de metas. Entretanto, foi perceptível que o mesmo não estava se sentindo a vontade 
em expor seus próprios objetivos, pois ao se deparar com o questionamento concedeu respostas breves, superficiais e genéricas, fator esse ressaltado por Mintzberg et al. (2000). Porém o gestor 1 salientou que no determinado momento que se estabelece uma meta consegue alcançá-la. Ao questionar os atuais objetivos da empresa, obteve-se como resposta a busca no aprimoramento da qualidade de produtos e serviços e como meta, citou melhorar o atendimento ao cliente, levando mais informações e orientações sobre os produtos. Já o gestor 2 , citou de forma mais clara e direta às ambições almejadas para a empresa, como objetivos na busca de aumentar o número de fornecedores, faturamento e a criação de uma sede própria como investimento à longo prazo. Como meta definiu que a prospecção de novos fornecedores, o que consequentemente elevaria as vendas tornando-se possível investir ainda mais no empreendimento.

Um aspecto interessante observado por meio da presente pesquisa foi a diferença existente entre a teoria e a prática dentro das pequenas empresas. Ficou nítido desde o início da pesquisa, que os gestores estão repletos de informações e experiências empíricas. No entanto, se tratando de explicações sobre os processos da empresa e em estabelecer de forma descritiva o que é realizado na prática, há dificuldades significativas.

Vale ressaltar que em muitos casos há restrição ou há dificuldade de expressar as ações da empresa em relação a informações referentes às metas e objetivos, o que demonstra a possível falta de planejamento de médio e longo prazo, uma vez que os afazeres de curto prazo e às questões operacionais do dia a dia consomem um elevado tempo e dificultam eventuais planejamentos futuros. Porém, para os gestores o envolvimento apenas nas questões emergenciais e operacionais acarreta riscos à própria sustentabilidade da organização, como comenta Quadros (2012).

Destaca-se também que a empresa estudada encontra-se em uma cidade onde se localiza uma filial da empresa JBS, líder mundial em processamento de carne bovina, ovina e de aves, além de ter uma forte participação na produção de carne suína. Na unidade de negócios situada no mesmo município é realizado o abete de aves. A atitude da empresa em estudo, de investir em algo no segmento da bovinocultura e não no aviário, pode ser identificado como uma estratégia da empresa.

\section{Conclusão}

Ao longo do trabalho realizado evidenciou-se a importância que há nas atividades relacionadas ao agronegócio, destacando o imenso potencial que este setor oferece ao Brasil. Expondo a importância de se realizar um planejamento estratégico que seja o mais detalhado possível, de forma a aumentar as possibilidades de sucesso da empresa atuante no agronegócio.

Com base nos fatores analisados na pesquisa, foi possível evidenciar que o planejamento estratégico, atua como um instrumento de aperfeiçoamento do conhecimento próprio da empresa.

Em um contexto estratégico a formulação de missão, visão e valores de uma empresa representam sua própria identidade, em relação a seus colaboradores, clientes e fornecedores. Já os objetivos indicam o que a empresa deseja alcançar, e com a elaboração das metas criam-se caminhos para promover e alcançar de forma mais eficaz os objetivos estabelecidos.

Com relação à variação do ambiente externo (oportunidade e ameaças) e ambiente interno (pontos fortes e pontos fracos), foi possível a verificação de alguns aspectos, como a qualidade dos produtos e serviços oferecidos pela empresa. No entanto, há um crescimento limitado do negócio, devido aos poucos fornecedores que atualmente a empresa trabalha o que pode ocasionar a perda de vendas e posteriormente dos clientes.

A partir do cumprimento dos objetivos deste estudo, foram estudadas as intenções estratégicas para a empresa e elaborado um diagnóstico da atual situação da empresa em relação ao seu ambiente interno e externo. Tais ações tornaramse possíveis por meio de análise do questionário, com a percepção das opiniões de cada gestor. Buscar resgatar de forma documental e através de rotinas periódicas a gestão estratégica da empresa de forma que se retroalimente, buscando assim ampliar o conhecimento e a memória da própria organização e tornar a tomada de decisão mais acurada e rápida, podendo desta forma, em um futuro próximo, avaliar e medir o desempenho das ações definidas e planejadas.

Sugere-se a continuidade deste estudo para o desenho do mapa estratégico da empresa. Por fim, sugerem-se ainda, como pesquisas futuras a 
análise de outras organizações de pequeno porte do agronegócio, para uma comparação entre os achados, como também, uma análise dentro da própria empresa em tempos futuros para observar seus avanços relacionados ao seu amadurecimento na gestão estratégica.

\section{Referências bibliográficas}

Almeida, M.I.R. Manual de planejamento estratégico. São Paulo: Editora Atlas, 2009.

Araújo, M. J. Fundamentos do Agronegócio. 2. ed. São Paulo: Atlas, 2007. 160 p.

Barbalho, C. R.. Planejamento Estratégico:uma análise metodológica. Londrina, v. 2, n. 1, p. 29-44, jan./jul. 1997.

Bilibio, C. Planejamento estratégico na empresa agrícola familiar.São Luiz: EDUFMA, 2009. 180 p.

Buainain, A. M. \& Batalha, M. O.. Cadeia Produtiva de carne bovina. Disponível em: <http://www.iica.org.br/Docs/CadeiasProduti vas/Cadeia\%20Produtiva\%20da\%20Carne\%2 0Bovina\%20c\%20capa.pdf>. Acesso em: 13 maio 2013.

Campos, W. O que é a gestão estratégica? Disponível em: <http://www.espm.br/rjclipping/2011/agosto/3 5691.pdf $>$. Acesso em: 20 jun. 2013.

Cavalcanti, M. Gestão estratégica de negócios: Evolução, Cenários, Diagnósticos e Ação. 2ed. São Paulo: Thomson, 2007.

Certo, S. C. PETER, J. P.Administração Estratégica:Planejamento e implantação da estratégia. São Paulo: Makron Books, 1993.

Crozatti, J. Modelo de gestão e cultura organizacional:Conceitos e interações. Caderno de Estudos FIPECAFI, São Paulo, v.10, n. 18, p. 01-20, maio/agosto 1998.

Dantas, N. G. S. \& Melo, R. S. O método de análise SWOT como ferramenta para promover o diagnóstico turístico de um local: o caso do município de Itabaiana / PB. Caderno Virtual de Turismo, v. 8, n. 1, p.118-130, 2008.

Ferreira, A. Sebrae lista os 6 maiores erros de quem vai à falência; saiba como evitá-los. Disponível em: $<$ http://economia.uol.com.br/ultimasnoticias/redacao/2012/04/04/sebrae-lista-os-6maiores-erros-de-quem-vai-a-falencia-saiba- como-evita-los.jhtm>. Acesso em: 03 abr. 2013.

Godet, M. A "Caixa de ferramentas" da prospectiva estratégica. 2000. Disponível em:

<http://www.turismorural.org.br/download/20 080615095245.pdf $>$. Acesso em: 20 jun. 2013.

Kaplan, R. S. \&Norton, D. P.Strategic maps: converting intangible assets into tangible outcomes. Massachusetts: Harvard Business School Publishing, 2004. 457p.

Kim, I. M, Chan W. \& Mauborgne, R. A estratégia do oceano azul: como criar novos mercados e tornar a concorrência irrelevante. Rio de Janeiro: Elsevier, 2005. 241p.

Kotler, P.. Administração de Marketing: análise, planejamento, implementação e controle. 2. ed. São Paulo: Atlas, 1993.

Luchiari Filho, A.. Produção de carne bovina no Brasil qualidade, quantidade ou ambas? In: Simpósio sobre desafios e novas tecnologias na Bovinocultura de Corte, 2006, Brasília, p. 1-10. Anais eletrônicos.Disponível em: <http://www.abccriadores.com.br/newsite/ima ges/Artigos/produo\%20de\%20carne\%20bovin a\%20no\%20brasil.pdf $>$. Acesso em: 14 maio 2013.

Mintzerb, H., Ahlstrand, B \& Lampel, J. Safári de estratégia. São Paulo: Artmed, 2000. 299 p.

Morrison, F. B.. Alimentos e alimentação dos animais. 2. ed. São Paulo: Editora da Universidade de São Paulo, 1966. 892 p.

Neves, M. F., Zylberstajn \& Neves, E. M.Agronegócio do Brasil. São Paulo: Saraiva, 2005. 152 p.

Oliveira, D. P. R. Planejamento Estratégico:Conceitos, metodologia e práticas. 20. ed. São Paulo: Atlas, 2004. 335 p.

Oliveira, B., Ross, E. S. \& Altimeyer, H. I. Proposta de um modelo de planejamento estratégico para instituições sem fins lucrativos.FAE, Curitiba, v. 8, n. 1, p.69-80, jan. 2005.

Porto, M. A. Missão e visão organizacional: orientações para a sua concepção. 1997. Disponível em: <http://www.jurandirsantos.com.br/outros_art 
igos/ec_missao_e_valores_organizacionais_or ientacoes_para_a_sua_concepcao.pdf>.

Acesso em: 14 jun. 2013.

Quadros, J. N. Planejamento Estratégico para Pequena Empresa: Um estudo de caso em uma pequena empresa De Santa Maria/Rs.Revista da Micro e Pequena Empresa, v. 6, n. 2, p.71-88, 2012.

Risk Management Agency. USDA. SWOT Analysis: a tool for making better business decisions. Disponível em: http://farm-riskplans.rma.usda.gov/pdf/ swot_brochure_web.pdf Acesso em: 07 jun. 2014.

Rocha, A. C. A Concepção estratégica e o planejamento. 1995. Disponível em: <http://www.betatreinamento.com.br/visita/C oncep $\% 20$ estrat $\% 20 \mathrm{e} \% 20$ planej.html $>$. Acesso em: 10jun. 2013.

Rodrigues, A. A. Estratégias de alimentação de bovinos em crescimento na época de seca. 1997. Disponível em: <http://www.infoteca.cnptia.embrapa.br/bitstr eam/doc/37677/1/PROCIDoc27SNE636.085L V.pdf>. Acesso em: 14 jun. 2014.

Scolari, D. G. Produção agrícola mundial: o potencial do Brasil. 2005. Disponível em: <http://www.abifina.org.br/arquivos/abf_publi cacoes/producao_agricola_mundial.pdf $>$.

Acesso em: 17 maio, 2013.

SEBRAE. Taxa de Sobrevivência das Empresas no Brasil. Disponível em: http://www.sebrae.com.br/Sebrae/Portal\%20S
ebrae/Anexos/Sobrevivencia_das_empresas_n o_Brasil_2011.pdf> Acesso em: 03 abr. 2014.

Silva, K. S. Nutrição Animal. 2012. Disponível em:

$<$ http://www.fazendao.com/artigos/nutricaoanimal/>. Acesso em: 14 maio 2013.

Tiffany, P. \& Peterson, S. D.Planejamento Estratégico: o melhor roteiro para um planejamento estratégico eficaz. Rio de Janeiro, Campus, 1988.

Toledo, J. C. \& Simões, J. M. S. Gestão do desenvolvimento de produto em empresas de pequeno e médio porte do setor de máquinas e implementos agrícolas do Estado de SP. Revista Gestão \& Produção, São Carlos, v.17, n.2, p. 257-269, 2010.

USDA. United States Department of Agriculture. PSD online home. Disponível em: <http://apps.fas.usda.gov/psdonline/> Acesso em: 11 junho 2014.

Vilela, N. J. \& Macedo, M. C. Fluxo de poder no agronegócio: o caso das hortaliças.Horticultura Brasileira, Brasília, v. 18, n. 2, p.88-94, jun. 2002.

\section{Recebido em Outubro 8, 2014.}

Aceito em Dezembro 18, 2014

License information: This is an open-access article distributed under the terms of the Creative Commons Attribution License, which permits unrestricted use, distribution, and reproduction in any medium, provided the original work is properly cited. 